\title{
Epidemiology of sepsis in brazilian icus: a nationwide stratified sample
}

\author{
FR Machado ${ }^{1,2,3^{*}}$, AB Cavalcanti ${ }^{3,4,5}$, F Bozza ${ }^{1,3}$, DC Angus ${ }^{6}$, EM Ferreira ${ }^{1}$, F Carrara ${ }^{1}$, J Lubarino ${ }^{1}$, R Salomao ${ }^{1,2}$, \\ LC Pontes de Azevedo ${ }^{1,2,3}$, on behalf of SPREAD investigators \\ From ESICM LIVES 2015 \\ Berlin, Germany. 3-7 October 2015
}

\section{Introduction}

Previous studies of the prevalence and fatality for sepsis in patients admitted to Brazilian intensive care units $(\mathrm{ICU})([1]-[3])$ were based on a small convenience sample, with most ICUs located in the wealthiest regions of the country. Thus, the current national sepsis prevalence, fatality rates and its associated risk factors are unknown.

\section{Objectives}

To assess prevalence, fatality rates and prognostic factors of severe sepsis and septic shock, in a stratified random sample of Brazilian ICUs.

\section{Methods}

A point prevalence study. The calculated sample size was 2,450 ICU beds to enroll 784 severe sepsis/septic shock patients. To generate the sampling frame, we created ten different strata, based on geoeconomic regions, considering hospitals located at state capitals or countryside and institutional profile (public or private), and randomly selected $13 \%$ of the ICUs in each stratum. All selected ICUs answered a websurvey regarding the availability of key clinical resources. We constructed a score based on the availability of 8 equal-weight items: ability to measure blood gases, lactate (both available in three hours); cultures (blood, urine and respiratory secretions), antibiotics (third-generation cephalosporins, carbapenems or piperacillin-tazobactam plus vancomycin or teicoplanin or linezolide), central venous catheters, crystalloids, norepinephrine and availability to measure central venous pressure. We considered as high availability those ICUs who always have all 8 items, intermediate

${ }^{1}$ Latin American Sepsis Institute, Sao Paulo, Brazil

Full list of author information is available at the end of the article availability those with 6-7 items and low availability those with 5 or less items. We included all patients with severe sepsis or septic shock hospitalized in the participants ICUs on one specific day (26/February/2014). We assessed demographic data, SAPS3 and compliance with sepsis treatment bundles and followed all patients until hospital discharge, truncated at 60 days.

\section{Results}

On the day of study there were 794 (29.6\%) patients with sepsis or septic shock among 2,705 patients already hospitalized or admitted in the 229 participant ICUs. The overall mortality rate was $55,7 \%$. Mortality was $57.8 \%(67 / 116)$ in the South, $51.2 \%(208 / 407)$ in the Southeast, 70\% (56/81) [f2] in Midwest, 58.3\% (77/136) in Northeast and $57.4 \%(31 / 54)$ in the North region $(\mathrm{P}=0.03)$. The mortality of public hospitals $(56.0 \%$; 253/452) was not different from the private ones (55.4\%; 186/336). Factors independently associated with a higher mortality rate are in Table 1.

\section{Conclusions}

Sepsis prevalence and mortality in Brazilian ICU are very high and represent a significant burden in critical care. Mortality is heterogeneous throughout Brazilian regions and is related to patients' characteristics but also to resource availability and adequate processes of care.

Table 1 Factors associated with mortality.

\begin{tabular}{llll}
\hline Variables & OR & $\mathbf{9 5 \% C l}$ & $\mathbf{p}$ value \\
\hline SAPS score & 1.04 & $1.03-1.05$ & $<0.001$ \\
\hline Antibiotics compliance & 0.67 & $0.46-0.97$ & 0.04 \\
\hline 6-h bundle compliance & 0.48 & $0.31-0.75$ & 0.001 \\
\hline Sepsis onset at ICU & 1.64 & $1.12-2.42$ & 0.01 \\
\hline Low availability of resources & 1.79 & $1.04-3.09$ & 0.04
\end{tabular}




\section{Grant Acknowledgment}

FAPESP - 2011/20401-4.

\section{Authors' details}

'Latin American Sepsis Institute, Sao Paulo, Brazil. ${ }^{2}$ Federal University of Sao

Paulo, Sao Paulo, Brazil. ${ }^{3}$ Brazilan Research in Intensive Care Network, Sao

Paulo, Brazil. ${ }^{4}$ Hospital do Coração Research Institute, Sao Paulo, Brazil.

${ }^{5}$ AMIBnet, Sao Paulo, Brazil. ${ }^{6}$ University of Pittsburgh, Pittsburgh, United

States.

Published: 1 October 2015

\section{References}

1. Silva E, et al: Crit Care 2004, 8(4):R251-60.

2. Sales JAL Jr, et al: Rev Bras Ter Intens 2006, 18(1):9-17.

3. Sogayar AM, et al: Pharmacoeconomics 2008, 26(5):425-34.

doi:10.1186/2197-425X-3-S1-A642

Cite this article as: Machado et al:: Epidemiology of sepsis in brazilian

icus: a nationwide stratified sample. Intensive Care Medicine Experimental 2015 3(Suppl 1):A642

\section{Submit your manuscript to a SpringerOpen ${ }^{\circ}$ journal and benefit from:}

- Convenient online submission

- Rigorous peer review

- Immediate publication on acceptance

- Open access: articles freely available online

- High visibility within the field

- Retaining the copyright to your article

Submit your next manuscript at springeropen.com 